\title{
Evaluation of cardiac autonomic functions of non diabetic offsprings of diabetic parents
}

\author{
Mehak Mufti ${ }^{1, *}$, Ravikiran Kisan², D.V. Deshpande ${ }^{3}$ \\ ${ }^{1}$ Lecturer, Dept. of Physiology, Government Medical College Srinagar, Jammu and Kashmir, ${ }^{2}$ Assistant Professor, Dept. of \\ Physiology, Kudugo Institute of Medical Sciences, Karnataka, ${ }^{3}$ Professor and Head, Dept. of Physiology, S.S. Institute of \\ Medical Sciences \& Research Centre, Davangere, Karnataka, India
}

*Corresponding Author:

Email: muftimehak@gmail.com

Received: $7^{\text {th }}$ April, 2018

Accepted: $7^{\text {th }}$ June, 2018

\begin{abstract}
Occurrence of autonomic imbalance is not very uncommon in diabetic patients and evidences of subclinical autonomic imbalance in their offsprings are also reported.

Objective: To study the effect of parental diabetes on cardiac autonomic functions of their non diabetic children.

Materials and Methods: The study was conducted in the department of Physiology SSIMS and RC, Davangere, after the approval of the institutional ethical committee, on 100 subjects. 50 non diabetic offsprings of diabetic parents (cases) and 50 non diabetic offsprings of non diabetic parents (controls). The subjects were in the age group of 18-25 years and were selected on the basis of predetermined inclusion exclusion criteria. The study protocol was explained and informed written consent was taken from the subjects. Battery of six conventional cardiac autonomic function tests were done which included, resting HR, HR response to deep breathing, HR response to Valsalva, DBP response to IGHT, BP and HR response to change in posture, BP response to CPT. Statistical analysis was done using Student's unpaired t test.

Result: Our results show decreased parasympathetic activity as indicated by increased basal HR $(\mathrm{p}<0.001)$, decreased HR response to DBT and VR ( $\mathrm{p}<0.004$ and 0.001 respectively) and increased maximum minimum HR ratio $(\mathrm{p}<0.002)$. There is an increased sympathetic activity also which can be inferred from an increased BP response to CPT in the cases when compared to the controls $(\mathrm{p}<0.01)$.

Conclusion: Our results show that there is a state of sympathovagal imbalance in the non diabetic offsprings of diabetic parents that can be inferred from an increased sympathetic activity and decreased parasympathetic activity.
\end{abstract}

Keywords: Diabetes mellitus, Autonomic function.

\section{Introduction}

Diabetes is emerging as an epidemic in the developing countries of the world. Evidences suggest that there is a stronger genetic predisposition to diabetes amongst Indians. ${ }^{1-3} \mathrm{DM}$ is a state of hyperglycemia in which carbohydrate and lipid metabolism is improperly regulated by insulin. ${ }^{4-7}$ Type 2 (Non-insulin dependent $\mathrm{DM}$ ) which is more prevalent form of diabetes, is characterized by varying degrees of insulin resistance, impaired insulin secretion and increased glucose production.

T2DM is a familial disease and the risk increases with increasing age particularly in the overweight and obese adults. Also the risk is greater if there is a family history of DM in the First Degree Relative (FDR). ${ }^{2,7,8-10}$ Insulin resistance has been observed in many non diabetic, FDR's of individuals with T2DM. ${ }^{7,11}$ Age at onset of diabetes is almost ten years early in non diabetic off springs of diabetic parents when compared to their parents. ${ }^{12}$

Sedentary life style, increased consumption of high calorie fatty food and aerated soft drinks lead to an increase in the incidence of DM, hypertension, obesity and dislipidemia which along with increase in the mental stress has further aggravated the problem. American heart association has designated DM as a major risk factor for the development of cardiovascular disorders. ${ }^{7}$ One of the complication is cardiac autonomic neuropathy which can remain asymptomatic for a long time. ${ }^{13}$ Patients may present with symptoms like resting tachycardia, loss of sinus arrhythmia, impaired valsalva manouvre, postural hypotension exercise intolerance, early fatigue and weakness, lightheadedness and syncope.

Since ANS prepares the body for the anticipated somatic and visceral requirements. ${ }^{5}$ In absence/disorders of ANS the ability to adapt to environmental stressors and challenges gets severely compromised. ${ }^{6}$ Evaluation of ANS is therefore widely used to assess the sympathetic and parasympathetic balance and diagnose many clinical conditions by the use of simple non invasive bed side provocative maneuvers like deep breathing test, isometric hand grip test, valsalva maneuver, cold pressor test, which are reliable and reproducible. These simple test can be used to identify the high risk group (although they may be asymptomatic) so as to make timely interventions in them. This will help to curb the incidence of diabetes and also help prevent serious complications like coronary heart disease, stroke, cardiac autonomic neuropathy, nephropathy, and retinopathy. 
Therefore the aim of our study was to evaluate the impact of parental T2DM on the cardiac autonomic functions of the non diabetic off-springs and to establish whether autonomic dysfunction is present.

\section{Materials and Methods}

The study was conducted in the department of Physiology SSIMS and RC, Davangere, after the approval of the institutional ethical committee, on 100 subjects. The study was initiated in December 2012 and completed in June 2014. Total of 50 non diabetic offsprings of diabetic parents (cases) and 50 non diabetic offsprings of non diabetic parents (controls) of age group 18-25 years were enrolled in the study.

Inclusion Criteria: Non diabetic off springs of diabetic parents in the age group of $18-25$ years were taken as cases and their age and gender matched healthy subjects with no family history of diabetes were taken as controls.

Exclusion Criteria: Subjects with history of diabetes, hypertension, congenital heart disease, smoking alcohol or substance abuse and with history of any medications that could influence cardiovascular and respiratory systems were excluded from the study.

The study protocol was explained and informed written consent was obtained from the study participants. Detailed personal, medical and family history including history of parental diabetes was taken. Menstrual history in case of females was taken. Height, weight, hip and waist circumference, hip waist ratio were measured was measured. All recordings were done in the morning between 8 am and 10 am with controlled temperature and humidity. Subjects were instructed to avoid tea /coffee in the morning. They were made familiar with the tests and resting 5 minute lead II ECG and Heart Rate (HR) were recorded by AD instruments - power lab 26T, Australia (Serial number T26-2756, model number ML856 and a battery of six autonomic tests was performed. Parasympathetic functions were assessed using basal heart rate, heart rate response to deep breathing and standing. Sympathetic functions were assessed by isometric handgrip test, cold pressor test, blood pressure response to standing. Valsalva maneuver is used to assess both sympathies and parasympathetic components.

Heart rate Response to Deep Breathing: Resting ECG and baseline Heart Rate (HR) were recorded. Subjects were asked to breathe deeply at the rate of 6 breaths per minute, allowing 5 seconds each in inspiration and expiration. The maximum and minimum heart rates during each breathing cycle were measured and the mean of the differences during three successive breathing cycles were taken to give the maximumminimum heart rate variation. Maximum minimum heart rate variation during deep breathing $\geq 15$ beats/minute is normal, 11-14 beats/minute is borderline and $\leq 10$ beats/minute is considered to be abnormal. ${ }^{14-16}$
Heart Rate Response to Valsalva Manoeuvre: Valsalva manoeuvre is described as forced expiration against closed glottis. ${ }^{6}$ Subjects nose was clipped by a nose clip and they were instructed to hold the mouth piece between teeth and lips, the other end of which was attached to a manometer. Baseline HR and Blood Pressure (BP) were recorded. The subjects were asked to blow into the mouth piece maintaining a pressure of $40 \mathrm{~mm}$ of $\mathrm{Hg}$ for 15 seconds. The HR normally increases during maneuver, followed by rebound bradycardia after the release. Procedure was repeated thrice. Valsalva ratio was taken as the mean of three successive readings. Valsalva Ratio (VR) is defined as the ratio of the longest R-R interval shortly after the maneuver to the shortest R-R interval during the maneuver. VR $>1.21$ is considered normal, between $1.11-1.20$ is borderline and $<1.10$ is abnormal. ${ }^{14-19}$

Diastolic Blood Pressure Response to Isometric Hand Grip Test: After recording the base line BP subjects were asked to hold the hand grip dynamometer in the dominant hand and compress the hand with maximum efforts. Procedure was repeated thrice and mean of the three readings which is called maximum isometric tension $\left(T_{\max }\right)$ was taken. Subjects were then asked to maintain a pressure of $30 \%$ of $\mathrm{T}$ max for 5 minutes. BP was recorded over the non exercising arm just before the release. The difference in the diastolic $\mathrm{BP}$ recorded just before the release of handgrip and the baseline was taken as the measure of the response. Variation in diastolic $\mathrm{BP} \geq 16 \mathrm{~mm}$ of $\mathrm{Hg}$ is normal, $11-15 \mathrm{~mm}$ of $\mathrm{Hg}$ is boderline, and $<10$ is abnormal. ${ }^{14,16}$

Blood Pressure and Heart Rate Response to Change in Posture: Subjects were asked to lie supine on the couch for 15 minutes with sphygmomanometer and ECG leads attached. Resting ECG (lead II), baseline HR, resting BP were recorded. Subjects were asked to stand and continuous ECG recording was done for 3 minutes. $\mathrm{BP}$ was recorded at 1 minute and 3 minutes after standing. HR at $15^{\text {th }}$ and $30^{\text {th }}$ beat after standing was noted to calculate $30: 15$ ratio. $30: 15$ ratio is the ratio of the longest $\mathrm{R}-\mathrm{R}$ interval occurring about 30 beats after standing to the shortest R-R interval which occurs about 15 beats after standing. Immediate heart rate response to standing (30:15 ratio) $>1.04$ is normal, $1.01-1.03$ is borderline and $<1.00$ is abnormal. Fall in systolic BP $<10 \mathrm{~mm}$ of $\mathrm{Hg}$ is normal, 11-29 is borderline and $>30 \mathrm{~mm}$ of $\mathrm{Hg}$ is abnormal. ${ }^{14,16,20,21}$

Blood Pressure Response to Cold Pressor Test: After recording the baseline BP subjects were asked to immerse their non dominant hand in ice cold water $\left(4^{\circ} \mathrm{C}\right)$ for 2 minutes. BP was recorded in the other arm at the end of two minutes and then compared with the baseline BP. The change in BP was then taken as the measure of the response. ${ }^{18,22-24}$ Normal responses consists of increase in the Systolic BP (SBP) by $20 \mathrm{~mm}$ of $\mathrm{Hg}$ and Diastolic BP (DBP) by $10 \mathrm{~mm}$ of $\mathrm{Hg}$. 
Statistical Analysis: The data was analyzed using students unpaired t test.

Result

Table 1: Anthropometrical parameters

\begin{tabular}{|l|c|c|c|}
\hline Anthropometrical parameters & Controls & Cases & P value \\
\hline & Mean \pm SD & Mean \pm SD & \\
\hline Height $(\mathrm{cm})$ & $165.08 \pm 8.60$ & $166.82 \pm 10.98$ & 0.38 \\
\hline Weight $(\mathrm{kg})$ & $60.52 \pm 9.84$ & $65.5 \pm 10.69$ & 0.17 \\
\hline Hip Circumference $(\mathrm{cms})$ & $31.40 \pm 4.31$ & $36.14 \pm 4.95$ & $<0.001^{* * *}$ \\
\hline Wasit Circumference $(\mathrm{cms})$ & $27.22 \pm 4.01$ & $31.82 \pm 4.46$ & $<0.001^{* * *}$ \\
\hline Hip: Waist ratio & $1.15 \pm 0.08$ & $1.14 \pm 0.11$ & 0.43 \\
\hline
\end{tabular}

$* \mathrm{p}<0.05, * * \mathrm{p}<0.01, * * * \mathrm{p}<0.001$

Table 2: Baseline cardiovascular (CVS) parameters

\begin{tabular}{|l|c|c|c|}
\hline Baseline CVS parameters & Controls & Cases & P value \\
\hline & Mean \pm SD & Mean \pm SD & \\
\hline HR $(\mathrm{bpm})$ & $68.50 \pm 4.01$ & $72.70 \pm 2.84$ & $<0.01^{* *}$ \\
\hline SBP $(\mathrm{mm}$ of $\mathrm{Hg})$ & $119.20 \pm 11.52$ & $121.32 \pm 11.18$ & 0.35 \\
\hline DBP $(\mathrm{mm}$ of $\mathrm{Hg})$ & $74.56 \pm 5.82$ & $76.60 \pm 8.63$ & 0.16 \\
\hline RBS & $130.36 \pm 7.55$ & $138.80 \pm 8.94$ & $<0.001^{* * *}$ \\
\hline
\end{tabular}

$* \mathrm{P}<0.05, * * \mathrm{p}<0.01, * * * \mathrm{p}<0.001$

Table 3: Effect of posture on heart rate

\begin{tabular}{|l|c|c|c|}
\hline \multicolumn{1}{|c|}{ Heart rate response } & Mean \pm SD & Mean \pm SD & \\
\hline Basal HR & $68.50 \pm 4.01$ & $72.70 \pm 2.84$ & $<0.001^{* * *}$ \\
\hline Maximum Minimum HR ratio & $1.13 \pm 1.43$ & $1.17 \pm 2.08$ & $0.002^{* *}$ \\
\hline
\end{tabular}

$* \mathrm{p}<0.05, * * \mathrm{p}<0.01, * * * \mathrm{p}<0.001$

Table 4: Comparison of VR amongst cases and controls

\begin{tabular}{|c|c|c|c|}
\hline VR & Controls & Cases & P value \\
\hline & Mean \pm SD & Mean \pm SD & \\
\hline VR & $1.55 \pm 0.28$ & $1.33 \pm 0.19$ & $<0.001^{* * *}$ \\
\hline
\end{tabular}

$* \mathrm{P}<0.05, * * \mathrm{p}<0.01, * * * \mathrm{p}<0.001$

Table 5: Comparision of response to cold pressor test amongst cases and controls

\begin{tabular}{|l|c|c|c|c|}
\hline BP response to CPT & Controls & Cases & P value \\
\hline & Mean \pm SD & Mean \pm SD & \\
\cline { 2 - 5 } Baseline SBP & $116.96 \pm 13.43$ & $117.72 \pm 19.54$ & 0.81 \\
\hline DBP Baseline & $71.64 \pm 5.20$ & $75.36 \pm 8.43$ & 0.09 \\
\hline SBP after release & $120.84 \pm 11.76$ & $121.92 \pm 11.99$ & 0.65 \\
\hline DBP after release & $74.28 \pm 6.41$ & $77.72 \pm 7.92$ & $0.01 * *$ \\
\hline
\end{tabular}

$* \mathrm{p}<0.05, * * \mathrm{p}<0.01, * * * \mathrm{p}<0.001$ 
Graph 1: Comparison of DBT amongst cases and controls

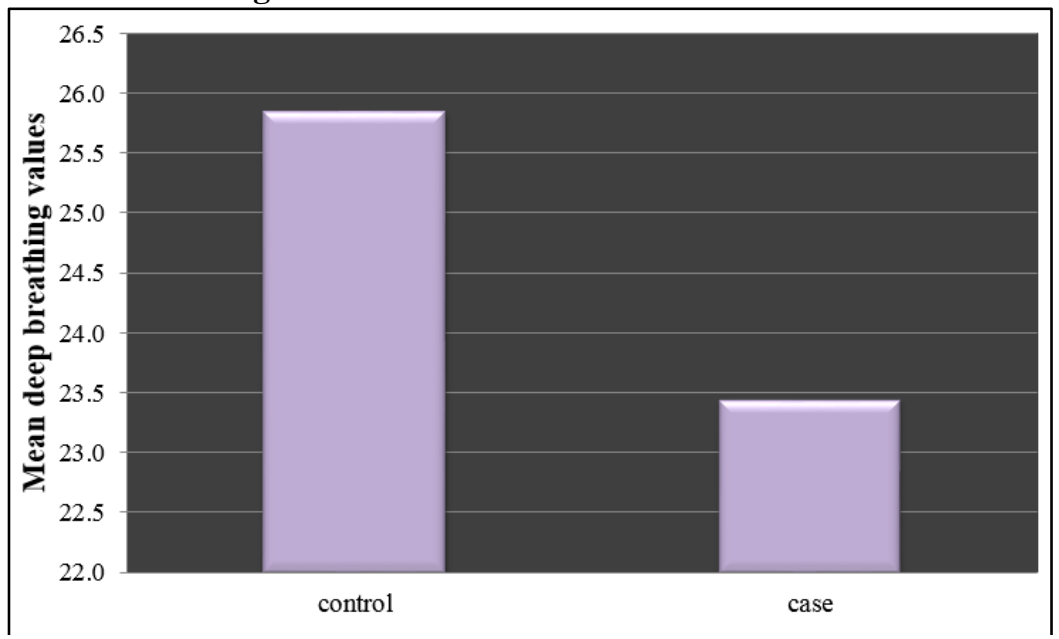

\section{Discussion}

Parasympathetic functions were assessed using the following tests. ${ }^{25,26}$ Basal HR, HR response to deep breathing test (DBT), Valsalva manoeuvre and to standing(30:15 ratio) Sympathetic functions were assessed by. ${ }^{25,26}$ IHGT, CPT, BP response to standing, HR response to Valsalva manoeuvre.

Table 2 shows basal HR was higher in the cases when compared to the controls. This is in accordance with the previous studies..$^{27,28}$ Basal HR is an index of vagal tone therefore increased HR implies decreased vagal tone and increased basal HR is associated with increased cardiovascular risk.

Table 3 increased maximum minimum HR ratio in the cases $(\mathrm{p}<0.002)$ indicates a decreased vagal tone in them when compared to the cases. Similar findings were confirmed by Gopal Krushna Pal et al in their study also. ${ }^{28}$

Graphs 1and Table 4 show statistically significant decrease in HR variation to DBT and VR amongst the cases when compared to the controls (p-0.004 and 0.001 respectively). This finding is in accordance with the previous studies. ${ }^{27-29}$ Although study by Sangeeta tuppad et al have given similar results but they were not found statistically significant. Decrease in HR variation in response to DBT and VR indicates decreased vagal activity. ${ }^{25}$

Table 5 shows the rise in DBP was more in the cases than in the controls ( $\mathrm{p}-0.01$ )

BP response to standing and IHGT: These tests are used to assess the sympathetic activity. DBP at 1 minute shows a significant difference between cases and controls. In IHGT, results show an increase in the SBP after release of the hand grip dynamometer in cases when compared to the controls but this was not statistically significant. Also DBP of both the groups did not show any change. But previous studies have shown statistically significant differences between the two groups. ${ }^{27,28}$ Inconclusiveness of this test in our study could be attributed to the lack of sensitivity due to the manual measurement of BP by mercury sphygmomanometer in contrast to the automatic BP monitor used in the other studies.

Exact mechanism of causation of sympathetic over activity is still not known. But it has been postulated that impaired nitric oxide synthesis could lead to sympathetic over activity and a state of insulin resistance. This predisposes an individual to a greater risk of hypertension, atherosclerosis and acute cardiovascular events.

Overall our study revealed a state of sympathovagal imbalance in the cases as compared to the controls. This was inferred from an increased sympathetic and a decreased parasympathetic activity in the cases when compared to the controls. The increased sympathetic activity in the offsprings of diabetic parents could be attributable to obesity, insulin resistance and a state of hyperinsulinemia. Vagal withdrawal and sympathetic over activity can increase an individual's risk of developing T2DM, hypertension, atherosclerosis, cardiovascular accidents and even a premature death. Impaired cardiovagal functions may increase the cardiovascular morbidity and mortality. Therefore, an early detection of risk factors associated with metabolic syndrome / DM is needed for implementation of appropriate preventive measures in the high risk groups.

\section{Conclusion}

Our study revealed a state of sympathovagal imbalance in the cases as compared to the controls. This was inferred from an increased sympathetic and a decreased parasympathetic activity in the cases when compared to the controls. The increased sympathetic activity in the offsprings of diabetic parents could be attributable to obesity, insulin resistance and a state of hyperinsulinemia. Vagal withdrawal and sympathetic over activity can increase an individual's risk of developing T2DM, hypertension, atherosclerosis, cardiovascular accidents and even a premature death. 
The modern westernized lifestyles can further aggravate the risk in the genetically predisposed population.

Impaired cardiovagal functions may increase the cardiovascular morbidity and mortality. Therefore, an early detection of risk factors associated with metabolic syndrome/DM is needed for implementation of appropriate preventive measures in the high risk groups. This study emphasizes on the usefulness and cost effectiveness of the conventional cardiac autonomic function tests in detecting the subtle/subclinical changes in the clinically asymptomatic cases.

\section{Limitation}

We did not estimate the plasma insulin levels and insulin resistance as on that basis subjects can be subdivided into insulin resistant and insulin sensitive groups which would establish the role of insulin resistance on cardiac autonomic functions.

\section{References}

1. Jali MV, Kambar S. Prevalence of diabetes amongst the family members of known diabetics. Int J Diab Dev Ctries. 2006;26(2):81-85.

2. Ramachandaran A. Type 2 diabetes in South Asians: Epidemiology, risk factors and prevention: In: Mohan V, Rao HRG, editors.1 ed : Jaypee brothers; 2007.p.1-39.

3. Raman PG. Diabetes mellitus. 3ed: A.I.T.B.S publishers New delhi; p.1-5.

4. Tiwari AK, Rao JM. Diabetes mellitus and multiple therapeutic approaches of phytochemicals : Present status and future prospects. Current science. 2002;83(1):30-8.

5. Visceral control mechanism: Visceromotor and autonomic nervous system.In:Tandon OP, Tripathi Y.editors.Best and taylors Physiological basis of medical practice.13 ed. Wolters Kluver. p1154-62.

6. Ganong WF. Review of medical physiology. $23^{\text {rd }} \mathrm{ed}$. McGraw-Hill; 2010. 315-322.

7. Alwin C. Diabetes mellitus.In :C Longo DL, Fauci AS, Kasper DL, Hauser SL, Jameson JL, Loscalzo J. editors. Harrison's principles of internal medicine. 18 ed.NY: McGraw hill; 2012. p.2968-3009.

8. Davidson's principles $\&$ practice of medicine. $21^{\text {st }} \mathrm{ed}$. Churchill Livingstone, Elsevier 2010. 795-834.

9. Diabtes mellitus and other disorders of metabolism. In: Kumar P, Clark M.editors.Kumar and Clarks clinical medicine. 7ed. Elsevier.p.1029-59.

10. Zafar U, Qureshi HJ, Sandhu QS, Ali Z. Frequency and association of family history of type 2 diabetes mellitus in type 2 diabetic patients. Pak J med health sci. 2013;7:1-3.

11. Mahanta BN, Mahnta TM. Clinical profile of persons with family history of diabetes mellitus with special reference to body fat percentage. J Assoc Physicians India. 2009;57:703-5.

12. Ramachandran A, Snehalatha C, Sivasankari S, Hitman GA, Vijay V. Parental influence on the spectrum of type 2 diabetes in the offspring among Indians. J Assoc Physicians India. 2007 Aug;55:560-2

13. Gulichsen E, Fleischer J, Ejskjaer N, Eldrup, Tarnow L. Screening for Diabetic Cardiac Autonomic Neuropathy Using a new handheld device. J Diabetes Sci Technol. 2012;6(4):965-72.

14. Ewing DJ, Martyn CN, Young RJ, Clarke BF. The value of cardiovascular autonomic function tests: 10 years experience in diabetes. Diabetes Care. 1985 Sep;8(5):491-8.
15. Fareedabanu AB, Gorkal AR, Narsimha SKR. A simple test of one minute heart rate variability during deep breathing for evaluation of sympathovagal imbalance in patients with type 2 diabetes mellitus. Pak J Physiol. 2011;7(1)33-6.

16. Ewing DJ, Clarke BF. Diagnosis and management of diabetic autonomic neuropathy. Br Med J. 1982;285:9168.

17. Soares JLD,Bento MS, Laranjo S, Andrade A, Soares ED, Boto JP et al. Wavelet analysis of autonomic outflow of normal subjects on head-up tilt, cold pressor test, Valsalva manoeuvre and deep breathing. Exp Physiol. 2007;92(4)677-86.

18. Nilekar AN, Patil VV, Kulkarni S, Vatve M. Autonomic function tests during pre and post menstrual phases in young women. Paravara Med Rev. 2011;6(2):24-30.

19. Das AK, Balchandar J, Chandraseka S. Autonomic neuropathy of heart in diabetes. Int J Diab dev countries. 1995;15:146-48.

20. Torsvik M, Haggblom A, Eide GE, SAachmutzhard E, Vetvik K, Winkler SA. Cardiovascular autonomic function tests in an African population. BMC Endocr Disord. 2008;8(19). doi: 10.1186/1472-6823-8-19

21. Khatoon N, Kumar BS, Hazari MAH. Cardiovascular autonomic neuropathy in patients with diabetes mellitus.Int J Pharm Bio Sci.2010;1(3)1-7.

22. Ritesh M, Karia MD, Rajput M, Hemant B, MehtA, Pradnya A, Gokhale. Blood Pressure Response to Cold Pressure Test in Normal Young Healthy Subjects: A Prediction of Future Possibilities of Hypertension. J Phys Pharm Adv. 2012;2(6)223-6.

23. Srivastava RD, Kumar M, Shinghal R,Sahay AP. Influence of age and gender on cold pressor response in indian population. Indian J Physiol Pharmacol. 2010;54(2)174-8.

24. Kavitha C, Jamuna BL, Vijayakumar GS. Pressor response during normal Menstrual cycle. Int J Biol Med Res. 2012;3(3)1975-81.

25. Pal GK. Textbook of medical Physiology. 2 ed. Ahuja publishing house 2007.p.203-22.

26. Shashank B, Niranjan M, Sendil K, Shomi A. Study of heart rate variability, fasting blood sugar and lipid profile in first degree relatives of patients with type 2 diabetes mellitus. Journal of advance researches in biological sciences. 2012;4(3):246-49.

27. Foss CH, Vestbo E, Froland A, Gjessing HJ, Mogensen CE, Damsgaard EM. Autonomic neuropathy in nondiabetic offspring of type 2 diabetic subjects is associated with urinary albumin excretion rate and 24-h ambulatory blood pressure: the Fredericia Study. Diabetes. 2001 Mar;50(3):630-6.

28. Pal GK, Adithan C., Ananthanarayanan PH, Pal P. Sympathovagal Imbalance Contributes to Prehypertension Status and Cardiovascular Risks Attributed by Insulin Resistance, Inflammation, Dyslipidemia and Oxidative Stress in First Degree Relatives of Type 2 Diabetics. PLOS ONE 2013;8(11):17.

29. Tuppad S, Sanganabasappa H, Aithala M, Bagali S..A study of glycemic status and parasympathetic functions in nondiabetic offsprings of type 2 diabetes mellitus. IJBAR 2012;3(12):887-90.

How to cite this article: Mufti $M$, Kisan $R$, Deshpande DV. Evaluation of cardiac autonomic functions of non diabetic offsprings of diabetic parents. Ind J Clin Anat Physiol. 2018;5(3):389-393. 